\title{
Impact of small group discussions on knowledge and attitudes of resident clinicians towards adverse drug reaction reporting in a tertiary care teaching hospital
}

\author{
Nehal A Shah ${ }^{1}$, Shruti V Brahmbhatt ${ }^{2 *}$, Sagun Desai ${ }^{3}$ \\ ${ }^{1}$ Assistant Professor, ${ }^{2}$ Associate Professor, ${ }^{1,2}$ Dept. of Pharmacology, ${ }^{1}$ Dr. M.K. Shah Medical College \& Research Centre, Ahmedabad, \\ Gujarat, ${ }^{2,3}$ Smt. B.K. Shah Medical Institute and Research Centre, Sumandeep Vidyapeeth Deemed University, Piparia, Vadodara, Gujarat, \\ India
}

\section{Corresponding Author: Shruti V Brahmbhatt}

Email: dr.shruti1988@gmail.com

\begin{abstract}
Introduction: Adverse drug reaction (ADR) reporting is largely dependent on spontaneous reporting by clinicians and health care teams. This in turn depends on their knowledge and attitudes. There is a need to develop sustainable, feasible and effective educational methods in order to improve ADR reporting rates.

Aim: To obtain baseline information regarding knowledge, attitudes and practice (KAP) of resident clinicians working in a tertiary care teaching hospital in respect to Pharmacovigilance activity and to demonstrate the effects of an educational intervention on knowledge and attitude components.

Materials and Methods: This was a prospective questionairre based interventional study. Two questionnaires were given before and after the intervention to 43 doctors across different levels of residency. Educational intervention had comprised of a 20-30 minute small group discussion on Pharmacovigilance. The questionnaire was structured to address the core objectives through 10 questions related to knowledge, 16 questions related to attitude and 2 questions related to practice. Descriptive statistics like mean, standard deviation, frequencies and percentages were used to analyze data. Statistical tests like t-test and $\mathrm{Chi}^{2}$ tests were used to examine group differences. Statistical significance was set at $\mathrm{p}<0.05$.

Results: The small group discussion brought about a significant change in response from before intervention to after intervention in $80 \%$ "knowledge" questions, and 46.15\% "attitude" questions. The change in response to "knowledge" questions was highly significant, very significant, significant and not significant in $6(60 \%), 1(10 \%), 1(10 \%)$, and $2(20 \%)$ questions respectively. The change in response to "attitude" questions was highly significant, very significant, significant and not significant in 1 (7.69\%), 2 (15.38\%), 3 (23.08\%), and 7 $(53.85 \%)$ questions respectively.

Conclusion: Our results demonstrate the need for and establish the effectiveness of educational interventions like small group discussions in improving knowledge and attitudes of resident clinicians in regards to adverse drug reaction reporting.
\end{abstract}

Keywords: Adverse drug reactions, Pharmacovigilance, KAP, Educational intervention, ADR reporting

\section{Introduction}

Adverse drug reaction (ADR) has been defined by the World Health Organization (WHO) as "a response to a drug that is noxious and unintended and occurs at doses normally used in man for the prophylaxis, diagnosis or therapy of disease, or for modification of physiological function" ${ }^{1}$ It is well established that adverse drug reactions (ADRs) increase mortality and morbidity in addition to the cost of healthcare. ${ }^{2}$ It is often assumed that adverse drug reactions are identified through several rounds of clinical trials. However clinical trials have their own limitations, including a homogenous population not representative of the target population, small sample size, limited duration, and inability to test the drug in a real world situation. ${ }^{3}$

Hence, once the drug reaches the market, efficient and accurate reporting from the health care practitioner prescribing drugs is essential to detect "true" adverse drug reaction incidence rates among different populations.

To identify adverse drug reactions after a drug has reached the market, "post marketing surveillance" or phase 4 clinical trials have been incorporated in the clinical trial framework. ${ }^{4}$ However, adverse drug reaction reporting still remains low.

Since 2010, to add momentum to the pharmacovigilance movement, the Pharmacovigilance
Programme of India (PvPI) has been instituted in India. ${ }^{5,6}$ Despite the presence of pharmacovigilance programs, ADR reporting largely depends on spontaneous reporting from health care professionals, which would also depend on their knowledge, and attitudes. ${ }^{7,8}$ Additionally, attitudes may differ according to location.

Hence it is important for hospitals to assess their own baseline "knowledge, attitudes, and practice" of clinicians/health care providers in relation to pharmacovigilance.

Clinical residents represent a subset of clinicians with a large potential to understand and implement appropriate ADR reporting systems. There is a need for developing sustainable, feasible and effective educational methods to improve ADR reporting rates. ${ }^{8}$ Such methods may include small group discussions. In the present study, we hypothesized that small group discussions, would signficantly affect knowledge and attitudes of resident clinicians with regard to pharmacovigilance and ADR reporting. 


\section{Aim and Objectives \\ Aim}

To establish a baseline for knowledge, attitude and practice of clinical residents working in a tertiary care teaching hospital rural area in respect to Pharmacovigilance activity and to see the effects of an educational intervention on the same.

\section{Objectives}

1. To generate baseline information about the knowledge, attitudes and practice of clinical residents in respect to Pharmacovigilance activity.

2. To enlist the possible reasons for inferior rates of ADR reporting, if any, and reasons for low level of awareness about ADR reporting

3. To check feasibility and effectiveness of educational methods like talks in small groups to improve knowledge and attitudes among clinical residents regarding ADR reporting.

\section{Materials and Methods}

This study was an analysis of Knowledge, Attitude and Practice in a group of clinical residents working in a tertiary care teaching rural hospital on one hand, clubbed with measuring impact of education on the same, carried out in a prospective manner, on the other hand. The study was conducted in the Dept. of Pharmacology, Smt. B.K. Shah Medical Institute and Research Centre and Dhiraj Hospital, a tertiary care teaching rural hospital, attached to Smt. B.K.Shah Medical Institute \& Research Centre, Piparia,Gujarat. Prior permission for carrying out the study was obtained from the Sumandeep Vidyapeeth Institutional Ethics Committee (SVIEC).

The entire study was carried out under 2 broad headings:

1. To assess the knowledge, attitude and practice (KAP) of clinical residents with regard to ADR detection and reporting from a tertiary care teaching hospital.

2. To examine the effect of educational intervention on knowledge and attitudes.

\section{Study Population}

A total of fourty three clinical residents were included in the study. Participants were explained purpose and method of the study using a Participant Information Sheet (PIS) and were included only after they signed an Informed Consent Form (ICF) willingly. Only participants actively practicing at Dhiraj hospital, pursuing post graduate (MD/MS/MDS) degree/diploma through residency programme and with M.B;B.S./B.D.S degree were included in the study.

\section{Study Design}

This was a prospective interventional study with 2 questionnaires given before and after the intervention to 43 doctors across different levels of residency at Dhiraj hospital. The questionnaire was adapted from studies conducted in Nigeria and the United Kingdom by Oshikoya et al. and Belton et al. ${ }^{7,10}$ The questionnaire included questions to obtain demographics of the residents, 10 questions related to knowledge, 16 questions related to attitude, and 2 questions related to practice.

\section{Data Collection}

The intervention consisted of a three step process: Step 1 A pre intervention questionnaire was distributed among various doctors able to participate in the study which was returned the same day. Step 2 - This was followed by a 20 30 minute group discussion with 2-3 participants at a mutually convenient time. The discussion was led by the investigator. Important aspects of Pharmacovigilance and adverse drug reaction reporting were discussed. Step 3Immediately after the discussion, participants were given the post intervention questionnaire.

\section{Statistical Methods}

Results of the interventional study were presented as mean \pm standard deviation. The effects of intervention on participant's knowledge and attitude was determined using a chi square test or appropriate $t$ test at $\mathrm{P}<0.05$ significant level.

\section{Results \\ Characteristics of Participants}

A total of 43 residents from clinical departments had participated in the study and had filled up the pre and post educational intervention questionnaire. Characteristics of participants are summarized in Table 1.

Table 1: Characteristics of Participants ( $=43$ )

\begin{tabular}{|c|c|c|}
\hline \multicolumn{2}{|c|}{ Characteristic } & Number n (\%) \\
\hline \multirow{2}{*}{ Sex } & Male & $26(60.47)$ \\
\cline { 2 - 3 } & Female & $17(39.53)$ \\
\hline \multirow{3}{*}{ Professional Level } & Range & $24-32$ Years \\
\cline { 2 - 3 } & Mean \pm SD & $27.16 \pm 1.96$ Years \\
\cline { 2 - 3 } & 1st Year Residents & $8(18.6)$ \\
\cline { 2 - 3 } & 2nd Year Residents & $11(25.58)$ \\
\hline \multirow{2}{*}{ Specialty } & 3rd Year Residents & $24(55.81)$ \\
\cline { 2 - 3 } & Internal Medicine & $7(16.28)$ \\
\cline { 2 - 3 } & Paediatrics & $7(11.63)$ \\
\cline { 2 - 3 } & Ophthalmology & $6(18.6)$ \\
\hline
\end{tabular}




\begin{tabular}{|c|c|c|}
\hline \multirow{4}{*}{} & Obstetrics And Gynecology & $4(9.3)$ \\
\cline { 2 - 3 } & Surgery & $4(9.3)$ \\
\cline { 2 - 3 } & Ent & $4(9.3)$ \\
\cline { 2 - 3 } & Orthopedics & $4(9.3)$ \\
\cline { 2 - 3 } & Anaesthesia & $4(9.3)$ \\
\hline Radiology & $3(6.98)$ \\
\hline
\end{tabular}

Influence of small group discussion on knowledge and attitudes

Pre and Post Intervention Knowledge Assessment

Responses to "knowledge" questions before (pre) and after (post) educational intervention by way of group discussion are summarized in table 2. A total of 10 questions were posed to participants. There was an increase in number of "yes" responses in $9(90 \%)$ questions by an average of 38.71\% \pm 24.64 (Mean \pm SD) and a decrease in $1(10 \%)$ question by $2.33 \%$ (not significant). The increase in 9 questions was highly significant, very significant, significant and not significant in $6(60 \%), 1(10 \%), 1(10 \%)$, and $1(10 \%)$ questions respectively. The average change in responses was $35.07 \% \pm 25.92$ (Mean \pm SD).Overall the change in response was highly significant, very significant, significant and not significant in $6(60 \%)$, $1(10 \%), 1(10 \%)$, and $2(20 \%)$ questions respectively. (Table 2$)$

Table 2: Pre and Post Educational Intervention (Group Discussion) Assessment of Knowledge Component ( $\mathrm{n}=43$ )

\begin{tabular}{|c|l|c|c|c|}
\hline S. No. & \multicolumn{1}{|c|}{ Question (yes/no) } & $\begin{array}{c}\text { Number n(\%) of "Yes" Answers } \\
\text { Intervention }\end{array}$ & $\begin{array}{c}\text { Post } \\
\text { Intervention }\end{array}$ & Pvalue \\
\hline 1 & $\begin{array}{l}\text { Clinicians are qualified to report adverse reactions to } \\
\text { drugs }\end{array}$ & $41(95.35)$ & $40(93.02)$ & 0.807 \\
\hline 2 & $\begin{array}{l}\text { Nurses are qualified to report adverse reactions to } \\
\text { drugs }\end{array}$ & $21(48.84)$ & $35(81.40)$ & 0.001 \\
\hline 3 & $\begin{array}{l}\text { Pharmacists are qualified to report adverse reactions } \\
\text { to drugs }\end{array}$ & $27(62.79)$ & $40(93.02)$ & $<0.001$ \\
\hline 4 & $\begin{array}{l}\text { Physiotherapists are qualified to report adverse } \\
\text { reactions to drugs }\end{array}$ & $9(20.93)$ & $31(72.09)$ & $<0.001$ \\
\hline 5 & $\begin{array}{l}\text { Patients are qualified to report adverse reactions to } \\
\text { drugs }\end{array}$ & $12(28.39)$ & $34(79.07)$ & $<0.001$ \\
\hline 6 & $\begin{array}{l}\text { Aware of Pharmacovigilance Programme of India } \\
\text { (PvPI) }\end{array}$ & $10(23.26)$ & $39(90.70)$ & $<0.001$ \\
\hline 7 & $\begin{array}{l}\text { Aware of Pharmacovigilance Committee of SBKS } \\
\text { MI \& RC }\end{array}$ & $28(65.12)$ & $38(88.37)$ & 0.004 \\
\hline 8 & Able to fill out ADR (white form) & $2(4.65)$ & $35(81.40)$ & $<0.001$ \\
\hline 9 & ADRs of recently approved drugs must be reported & $33(76.74)$ & $39(90.70)$ & 0.02 \\
\hline 10 & Serious ADRs for established drugs must be reported & $39(90.70)$ & $40(93.02)$ & 0.585 \\
\hline
\end{tabular}

*ADR- Adverse Drug Reaction

\section{Pre and Post Intervention Attitude Assessment}

Responses to "attitude" questions before (pre) and after (post) educational intervention by way of group discussion are summarized in table 3. A total of 16 questions were posed to participants. Of these, 13 were attitudes targeted by the intervention. From questions targeted by intervention, the average change in responses was $16.28 \% \pm 17.96$ (Mean \pm SD). Of these the change in response was highly significant, very significant, significant and not significant in 1 (7.69\%), 2 $(15.38 \%), 3(23.08 \%)$, and 7 (53.85\%) questions respectively. (Table 3)

Table 3: Pre and Post Educational Intervention (Group Discussion) Assessment of Attitude Component $(\mathrm{n}=43$ )

\begin{tabular}{|c|l|c|c|c|}
\hline S. No. & \multicolumn{1}{|c|}{ Question (yes/no) } & Number n(\%) of "Yes" Answers & Pvalue \\
\hline & & Pre Intervention & $\begin{array}{c}\text { Post } \\
\text { Intervention }\end{array}$ & \\
\hline 1 & Would report any serious ADRs & $41(95.35)$ & $40(93.02)$ & 0.585 \\
\hline 2 & Would report any unintended / unexpected ADRs & $38(88.37)$ & $41(95.35)$ & 0.185 \\
\hline 3 & Would report ADR to a new drug & $41(95.35)$ & $39(90.7)$ & 0.35 \\
\hline 4 & Would report expected/known ADRs of a drug & $35(81.40)$ & $41(95.35)$ & 0.02 \\
\hline 5 & Would not report due to lack of incentives & $5(11.63)$ & $4(9.3)$ & 0.807 \\
\hline
\end{tabular}

IP International Journal of Comprehensive and Advanced Pharmacology, January-March, 2020;5(1):31-36 


\begin{tabular}{|c|l|c|c|c|}
\hline 6 & Would not report due to fear of extra work & $35(81.40)$ & $26(60.47)$ & 0.022 \\
\hline 7 & Would not report due to lack of time & $37(86.05)$ & $24(55.81)$ & 0.003 \\
\hline 8 & $\begin{array}{l}\text { Would not report as reporting } \\
\text { mild/expected/known ADR is unnecessary }\end{array}$ & $37(86.05)$ & $24(55.81)$ & 0.003 \\
\hline 9 & $\begin{array}{l}\text { Would not report due to pressure from } \\
\text { pharmaceutical companies }\end{array}$ & $2(4.65)$ & $3(6.98)$ & 0.242 \\
\hline 10 & $\begin{array}{l}\text { Would not report due to fear of blame/violence } \\
\text { from patient/family members of patient }\end{array}$ & $41(95.35)$ & $37(86.05)$ & 0.064 \\
\hline 11 & Reporting ADRs is a professional responsibility & $42(97.67)$ & $41(95.35)$ & 0.585 \\
\hline 12 & Single report would not make a difference & $30(69.77)$ & $21(48.83)$ & 0.012 \\
\hline 13 & ADR Form Is Too Complex To Fill & $40(93.02)$ & $12(27.91)$ & $<0.001$ \\
\hline 14 & ADR Reporting Should Be Compulsory & $6(13.95)$ & $5(11.63)$ & 0.585 \\
\hline 15 & ADR Reporting Should Be Voluntary & $38(88.37)$ & $39(90.70)$ & 0.242 \\
\hline 16 & Identity of reporter/prescriber should be hidden & $35(81.40)$ & $38(88.37)$ & 0.339 \\
\hline
\end{tabular}

*ADR- Adverse Drug Reaction

\section{Practice Assessment}

A total of 2 questions related to "practice" of ADR reporting were posed to participants. Twenty-eight participants $(65.12 \%)$ had witnessed an ADR before. None of the participants had ever reported an ADR. Two participants did not answer questions of the practice component.

\section{Discussion}

Despite the presence of pharmacovigilance programs, ADR reporting in India remains low. ADR reporting practice largely depends on spontaneous reporting from clinicians, which in turn depends on their knowledge and attitudes. ${ }^{7,8}$ Clinical residents are in the training period and we assumed they would be an appropriate target population for assessing baseline "knowledge,attitudes, and practice" and the effects of small group discussions on the same.

For the assessment of effects of small group discussion, a questionnaire was given before and after intervention. The small group discussion brought about a significant change in response from before intervention to after intervention in $80 \%$ "knowledge" questions and 46.15\% "attitude" questions. This shows that knowledge is the most susceptible to change due to group discussion. It remains more difficult to change attitude of respondents through merely group discussions. Changes in attitude would require more systematic changes as well like protection against litigation (provided by institute) and protection of identity. Khalili et.al reported improvements in both attitude and knowledge following educational inteventions. ${ }^{11}$

For 10 questions relating to "knowledge", nine showed an increase in number of "correct" responses while one showed a decreased in number of "correct" responses. The decline in correct responses to 1 question was not significant and response to that question had a high baseline $(95.35 \%$ correct) that could have prevented statistically significant increases. Most respondents $(95.35 \%)$ believed that "Doctors" are qualified to report adverse drug reactions. However only 21 to $63 \%$ believed others (other health care professionals and patients themselves) to be qualified to report ADRs. This is similar to results of other studies where it was demonstrated that most health care professionals believe only clinicians to be qualified for reporting ADRs. ${ }^{10,12,13}$ After the intervention most respondents agreed that anyone from physician to patient should be able to report adverse drug reactions.

Similarly, knowledge of the existence of PvPI, Pharmacovigilance Committee, and ADR reporting centre in the college/hospital was low at baseline $(23.26 \%, 65.12 \%$ and $58.14 \%$ respectively ) but improved significantly $(90.70 \%, 88.37 \%$, and $83.72 \%$ respectively) after the intervention. This lack of knowledge of existing systems in the hospital/college has also been reported in other studies. ${ }^{10,14,15,16}$ While a lack of awareness of existing reporting systems directly decreases ADR reporting rates, it can be addressed through appropriate awareness programmes.. These low numbers before intervention show ample potential for educational interventions to improve understanding and knowledge of adverse drug reaction reporting systems. Before intervention 93\% thought the ADR form was complex to fill, however after intervention only $27 \%$ believed so showing the effectiveness of intervention in explaining ADR forms. Similarly before intervention only $4.65 \%$ were able to fill out ADR form compared to $81.40 \%$ after intervention.

Most respondents (90.7\%) understood that all serious reactions should be reported even before the intervention.This was expected. However, clinicians should be discouraged from only reporting serious reactions. Others studies have also reported a tendency of clinicians to report only serious ADRs should be reported. ${ }^{10,13}$ This should be addressed and an increased emphasis is required on reporting of expected/known/mild ADRs.

Of the 16 "attitude" questions posed to participants, 13 were questions wherein a "positive" or "negative" attitude could be ascribed. Of these 13 questions, significant change from negative attitude to positive attitude was seen in $6(46.15 \%)$ questions. Of the 7 questions that did not show significant "improvement" from pre to post intervention 6 were due to high baseline numbers (showing positive attitudes) that prevented statistically significant increases. The other question related to fear of being blamed and violence from patient/family members. Notably, over $95 \%$ 
feared blame on Doctor before intervention and this did not change significantly after intervention. It is possible that this factor requires institutional and systematic policy changes in terms of support given to Doctors.

Intervention was significantly effective in further sensitizing clinicians even if the ADR was well recognized/mild. Most respondents in our study would report an ADR that is unusual, serious or due to a new drug. This is in accordance to most other studies ${ }^{10,13}$.Despite a relatively high baseline, the intervention significantly improved the number respondents ready to report ADR of a newly approved drug. A study by Khan et al. demonstrated that $77.9 \%$ of respondents believed all serious ADRs of a given drug were known during the clinical trial stage. ${ }^{17}$ Hence interventions should be aimed at educating participants that all ADRs should be reported and not just unusual, serious and new product ADRs.

Prior to educational intervention most respondents believed that ADR reporting may take extra time out of their schedule $(86.05 \%)$ and may generate extra work $(81.40 \%)$. They also did not feel like a single report may make a difference $(97.67 \%)$. These factors changed significantly following intervention.

Incentives for reporting $(11,63 \%)$ and pressure from pharmaceutical companies $(4.65 \%)$ were not issues discouraging a majority of respondents before or after intervention.

Most (97.67\%) clinicians believed that ADR reporting is necessary by the profession. This is similar to results obtained by Iffat et al., and Sanghavi et al. ${ }^{12,18}$ This indicates positive attitude in relation to pharmacovigilance.

Very few believed in mandatory ADR reporting $(13.95 \%)$ while most believed it should only be on a voluntary basis $(88.37 \%)$. This is in contrast to studies where a majority of respondents believed ADR reporting should be compulsory. ${ }^{18,19}$ But our finding is in agreement with other studies from India where low proportion of respondents believed in mandatory ADR reporting ${ }^{20,21}$. It is important to note that the study population of both these studies were similar to our study (resident clinicians).

Most participants also believed that it was important to hide the identity of the prescriber $(81.40 \%)$ and reporter $(83.72 \%)$. This may be due to a fear of litigation or blame or even violence by patients or their family members.

Interestingly, though $65 \%$ had seen someone suffering from an ADR, none had reported it. Other studies have reported similar findings with high proportion of respondents coming across ADRs and low proportion of respondents actually reporting ADRs. ${ }^{13-15,18,19,21,22}$ We hope that interventions like small group discussions can serve to improve adverse drug reaction reporting rates.

\section{Limitations}

Our findings are limited to clinical residents. Future studies can focus on long term impact of educational interventions on practice and ADR reporting rates specifically.

\section{Conclusion}

Overall we were able to meet all of the aims outline in the beginning of the study. Our baseline questionnaire suggested low knowledge and attitude of clinical residents at Dhiraj Hospital. Educational interventions like group discussions are feasible and effective at improving knowledge and attitudes of residents. Regularly held educational interventions may improve knowledge and attitude of clinical residents which subsequently may lead to an increase in adverse drug reaction reporting rates.

\section{Financial support and sponsorship \\ None.}

\section{Conflicts of interest}

None.

\section{Ethical approval}

The study was approved by the Institutional Ethics Committee

\section{References}

1. World Health Organization. International drug monitoring: the role of national centres. Report of a WHO meeting. World Health Organ Tech Rep Ser 1972;498:1-25.

2. Moore N, Lecointre D, Noblet C, Mabille M. Frequency and cost of serious adverse drug reactions in a department of general medicine. Br J Clin Pharmacol 1998;45(3):301-8.

3. Alomar MJ. Factors affecting the development of adverse drug reactions (Review article). Saudi Pharm J 2014;22(2):83-94.

4. Suvarna V. Phase IV of Drug Development. Perspect Clin Res 2010;1(2):57-60.

5. Kalaiselvan V, Thota P, Singh GN. Pharmacovigilance Programme of India: Recent developments and future perspectives. Indian J Pharmacol 2016;48(6):624-8.

6. Kalaiselvan V, Prakash J, Singh GN. Pharmacovigilance programme of India. Arch Pharm Pract 2012;3(3):229-32.

7. Belton KJ, Lewis SC, Payne S, Rawlins MD, Wood SM. Attitudinal survey of adverse drug reaction reporting by medical practitioners in the United Kingdom. Br J Clin Pharmacol 1995;39(3):223-6.

8. Gurmesa LT, Dedefo MG. Factors Affecting Adverse Drug Reaction Reporting of Healthcare Professionals and Their Knowledge, Attitude, and Practice towards ADR Reporting in Nekemte Town, West Ethiopia. Biomed Res Int 2016;2016:5728462.

9. Johansson ML, Hägg S, Wallerstedt SM. Impact of information letters on the reporting rate of adverse drug reactions and the quality of the reports: a randomized controlled study. BMC Clin Pharmacol 2011;11:14.

10. Oshikoya KA, Awobusuyi JO. Perceptions of doctors to adverse drug reaction reporting in a teaching hospital in Lagos, Nigeria. BMC Clin Pharmacol 2009;9:14.

11. Khalili H, Mohebbi N, Hendoiee N, Keshtkar AA, DashtiKhavidaki S. Improvement of knowledge, attitude and perception of healthcare workers about ADR, a pre- and postclinical pharmacists' interventional study. BMJ Open 2012;2(1):e000367

12. Abubakar AR, Simbak NB, Haque M. A systematic review of knowledge, attitude and practice on adverse drug reactions and pharmacovigilance among doctors. J Appl Pharm Sci 2014;30;4(10):117-27.

13. Sanghavi DR, Dhande PP, Pandit VA. Perception of pharmacovigilance among doctors in a tertiary care hospital: 
influence of an interventional lecture. Int J Risk \& safety Med 2012;25(4):197-204.

14. Kiran LJ, Shivashankaramurthy KG, Bhooma S, Dinakar KR. Adverse drug reaction reporting among clinicians in a teaching hospital in south Karnataka. Scholars J Appl Med Sci 2014;2(1D):399-403.

15. Chopra D, Wardhan N, Rehan HS. Knowledge, attitude and practices associated with adverse drug reaction reporting amongst doctors in a teaching hospital. Int J Risk \& Safety Med 2010;23(4):227-32.

16. Shailesh NA, Ranjana KA, Kumar VS, Satish BA. Impact of Educational Intervention on Knowledge, Attitude and Practice of Pharmacovigilance among Medical Graduates of Rural Tertiary Care Teaching Hospital of Central India. Mintage J Pharm Med Sci 2013;2(2):51-4.

17. Khan SA, Goyal C, Chandel N, Rafi M. Knowledge, attitudes, and practice of doctors to adverse drug reaction reporting in a teaching hospital in India: An observational study. J Nat Sci Biol Med 2013;4(1):191-6.

18. Iffat W, Shakeel S, Rahim N, Anjum F, Neesar S, Ghayas S et al. Pakistani physicians' knowledge and attitude towards reporting adverse drug reactions. Afr J Pharm Pharmacol 2014;8(14):379-85.
19. Bisht M, Singh S, Dhasmana DC. Effect of educational intervention on adverse drug reporting by physicians: a crosssectional study. ISRN Pharmacol 2014;2014:259476.

20. Gupta P, Udupa A. Adverse drug reaction reporting and pharmacovigilance: Knowledge, attitudes and perceptions amongst resident doctors. J Pharm Sci Res 2011;3(2):1064-9.

21. Pimpalkhute SA, Jaiswal KM, Sontakke SD, Bajait CS, Gaikwad A. Evaluation of awareness about pharmacovigilance and adverse drug reaction monitoring in resident doctors of a tertiary care teaching hospital. Indian J Med Sci 2012;66(34):55-61.

22. Desai CK, Iyer G, Panchal J, Shah S, Dikshit RK. An evaluation of knowledge, attitude, and practice of adverse drug reaction reporting among prescribers at a tertiary care hospital. Perspect Clin Res 2011;2(4):129-36.

How to cite: Shah NA, Brahmbhatt SV, Desai S. Impact of small group discussions on knowledge and attitudes of resident clinicians towards adverse drug reaction reporting in a tertiary care teaching hospital. IP Int J Comprehensive Adv Pharmacol 2020;5(1):31-6. 